Amanda Reilly*

\title{
VOICE AND GENDER INEQUALITY IN NEW ZEALAND UNIVERSITIES
}

\begin{abstract}
New Zealand universities exhibit a typical gender hierarchy with women predominating in lower status and less well-paid roles. This is despite the fact universities are governed by regulations prohibiting discrimination. Literature on gender inequality in universities suggests that the causes for this are structural and systemic.

Voice mechanisms, such as ensuring there are women on decision making committees, may improve gender equality and thus compliance with the law. However, this article draws on organisational and other literature to argue that the benefits of this are limited; women do not all 'speak with one voice' and the experience of gender may divide women as much as it unites them. There are also risks for individual women who speak out regarding gender inequality which may result in them choosing to remain silent. It is concluded that those seeking to design effective voice mechanisms as well as universities seeking to comply with their legal obligations should be sensitive to the limitations of voice.
\end{abstract}

\section{INTRODUCTION}

$\mathrm{N}$ ew Zealand prides itself on being the first country in the world to grant women the vote. It has had two female Prime Ministers. Yet despite the successes of a few high-profile women, progress towards equality and pay equity has stalled. Senior levels of most sectors remain dominated by men. New Zealand universities exhibit a typical gender hierarchy with women predominating in lower status and less well-paid roles. ${ }^{1}$ This is despite the fact universities are governed by regulations intended to promote equal employment opportunities ('EEO') and prohibit discrimination.

This article considers how voice as a mechanism may or may not be helpful in terms of improving gender equality (and thus compliance with the law) within universities. Its central thesis is that while voice may have a part to play in improving gender inequality in universities, it has some limitations. While discussion is focused on women in New Zealand universities much of the analysis on the limitations of voice is applicable to other minorities in other institutions.

\footnotetext{
Law Lecturer, Victoria University of Wellington (New Zealand).

1 New Zealand Human Rights Commission, New Zealand Census of Women's Participation (Report, 2010).
} 
The article is structured as follows: First, the regulatory framework surrounding New Zealand universities is described. Secondly, the reasons why women continue to predominate in lower status roles are considered and it is concluded that structural and subtle forms of gender bias and discrimination are, at least in part, to blame. Thirdly, some problematic aspects of expecting individual women to address discrimination through exercise of voice are discussed. It is argued that women do not all 'speak with one voice' and the experience of gender may divide women as much as it unites them. There are also risks for individual women who speak out regarding gender inequality which may result in them choosing to remain silent. The conclusion summarises the implications of this analysis.

\section{The Regulatory Framework of New Zealand's Universities}

'Regulation' encompasses more than legal instruments such as primary and delegated legislation. Black suggests that regulation is 'the sustained and focused attempt to alter the behaviour of others according to defined standards or purposes with the intention of producing a broadly identified outcome or outcomes'?

While individual organisations are located within an external legal framework, organisations have their own internal regulatory structures which are shaped in response to the law. The external legal framework New Zealand's universities are located within is comprised of the following elements. New Zealand has ratified the Convention on the Elimination of All Forms of Discrimination against Women. As such, it is committed to taking all appropriate measures to eliminate discrimination against women in the field of employment and recognising that women have the right to the same employment opportunities, equal remuneration and equal treatment in respect of work of equal value, as well as equal treatment in the evaluation of the quality of the work. ${ }^{3}$ The Human Rights Act 1994 (NZ) prohibits direct and indirect discrimination against women in the workplace. The Equal Pay Act 1972 (NZ) provides for equal pay for women for the same or similar work in both the public and private sectors. ${ }^{4}$

New Zealand's universities have responded to this external legal framework by stating Equity Objectives in their strategic plans, developing EEO Policies, appointing Pro-Vice Chancellors with responsibility for Equity, and establishing Equity Committees at both university-wide and individual faculty level.

Promotions processes generally have an independent Equity Observer as well as a Union Observer. The Tertiary Education Union represents both academic and

2 Julia Black, 'Critical Reflections on Regulation' (2002) 27 Australian Journal of Legal Philosophy 1, 20.

3 Convention on the Elimination of All Forms of Discrimination Against Women, opened for signature 18 December 1979, 1249 UNTS 13 (entered into force 3 September 1981) arts 11(1)(b), 11(1)(d).

$4 \quad$ New Zealand Human Rights Commission, Tracking Equality at Work (Report, 2011). As discussed by Margaret Wilson in the report, this legislation is not particularly effective as there is no transparency around remuneration rates in New Zealand. 
general staff in New Zealand universities and it too has structures in place intended to address gender inequality. Local branch committees have a designated Women's Representative' and at the national level there is a national Women's Committee with a Women's Vice President. Collective agreements typically make reference to the employer's commitment to EEO.

\section{Universities Remain as Gendered Hierarchies}

Despite laws and policies prohibiting discrimination and promoting EEO, women hold only 22.45 per cent of senior academic positions in New Zealand's eight universities. ${ }^{5}$ Women also dominate the so-called 'ivory basement' of lower level tutors and research assistants, often on short-term contracts with limited opportunities for advancement. ${ }^{6}$ It is clear that a glass ceiling exists for women academics. At the same time, female-dominated administrative staff represents an example of occupational segregation; a pink collar ghetto of women clustered in lower status and lower paid occupations. Thus it would appear that 'the rhetoric of policies concerning equity issues, academic fairness and equality, through which academic institutions image themselves, is belied too often by their practices'. ${ }^{7}$ There is nothing unique about these patterns, which are replicated in other universities as well as other sectors internationally. ${ }^{8}$

There is a well-established body of research advancing a variety of explanations for the general state of women's persistent inequality within organisations. At a fundamental level, according to Acker, organisational structures are not gender neutral. Instead, assumptions about gender are deeply embedded in the structure of organisational logic. ${ }^{9}$ As such, gender hierarchies are not necessarily a product of conscious conspiracies against individual women but instead are a consequence of the regular operation of standard operating procedures. ${ }^{10}$ For example, ostensibly neutral job evaluations are not neutral in that the skills more often found in men's jobs receive more points than the skills found in women's jobs. ${ }^{11}$ Status is awarded to jobs on the basis of their perceived level of complexity and responsibility. 'Lower-level' positions, ie, the level of most jobs filled predominantly by women, are assumed to have 'low levels' of complexity and responsibility. Complexity and responsibility are

$5 \quad$ Human Rights Commission, above n 1,83.

6 Colin Bryson, 'The Consequences for Women in the Academic Profession of the Widespread Use of Fixed Term Contracts' (2004) 11 Gender Work and Organization 187.

7 Janet Mansfield and Shirley Julich, 'Researching Women at Auckland University of Technology' (2006) 25 Critical Perspectives on Communication, Cultural and Policy Studies $17,23$.

$8 \quad$ Laura Kessler, 'Keeping Discrimination Theory Front and Center in the Discourse over Work and Family Conflict' (2007) 34 Pepperdine Law Review 313, 316.

9 Joan Acker, 'Hierarchies, Jobs, Bodies: A Theory of Gendered Organizations' (1990) 4 Gender and Society 139, 146.

$10 \quad$ Patricia Roos, 'Together but Unequal: Combating Gender Inequality in the Academy' (2008) 13 Journal of Workplace Rights 185, 187.

11 Acker, above n 9, 150. 
defined so as to reinforce these assumptions. Hence 'the child-care worker's responsibility for other human beings or the complexity facing the secretary who serves six different, temperamental bosses can only be minimally counted if the congruence between position level, responsibility and hierarchy is preserved'. ${ }^{12}$

Bird translates this to an academic context:

the segregation of academic disciplines and institutions, the construction of faculty and administrative roles in ways that are more consistent with men's lives and the maintenance of evaluation processes that disproportionately value the disciplines and activities that men dominate are all examples of how university structure and associated cultures and practices are gendered. ${ }^{13}$

Another explanation for female predominance in lower status roles is historical discrimination which has subsequently been remedied so that more women are now moving through the 'pipeline'. However, a number of studies suggest that the 'pipeline' is leaky and that women are not moving up it in sufficient numbers to support the view that women now face a level playing field. ${ }^{14}$ Furthermore, Baker notes in recent years, equity initiatives in universities have been counteracted by increased managerialism and research audit regimes which have intensified unequal outcomes for women. ${ }^{15}$

It is sometimes suggested that women choose low status, low paid positions. However, the fact that women often have to manage greater family responsibilities than their male colleagues undoubtedly feeds into such 'choices'. ${ }^{16}$ As noted by Kessler, while we all make decisions for complex reasons and all decisions can fairly be understood as personal it is also arguable that discrimination is a significant contributing factor to women 'choosing' secondary status. ${ }^{17}$ Work aspirations of individuals are shaped by the expectations of those around them and by their experiences. Research suggests discrimination contributes to the downsizing of women's dreams, lowered aspirations and reduced human capital investments in work..$^{18}$ It is questionable whether the same choices would have been made were discrimination absent.

Discrimination may be of two kinds: there is direct, personal and intentional discrimination and there is also indirect, impersonal and unintentional discrimination. Overt intentional discrimination and sexual harassment still occur in universities but, by and

\section{$12 \quad$ Ibid 149.}

13 Sharon R Bird, 'Unsettling Universities' Incongruous, Gendered Bureaucratic Structures: A Case Study Approach' (2011) 18 Gender, Work and Organization 202, 208.

14 Kessler, above n 8, 330.

15 Maureen Baker, 'Gender, Academia and the Managerial University' (2009) 24 New Zealand Sociology 24, 26.

16 Maureen Baker, 'Choices or Constraints? Family Responsibilities, Gender and Academic Careers' (2010) 41 Journal of Comparative Family Studies 1.

17 Kessler, above n 8, 331.

18 Ibid 322-4. 
large, patterns of discrimination, while entrenched, are less obvious. As explained by Sturm, contemporary discrimination is quite subtle and embedded 'in patterns of interaction, informal norms, networking, training, mentoring and evaluation'. ${ }^{19}$

In a university context, the concept of a 'chilly climate' is frequently utilised to explain the 'ubiquitous and insidious problem of subtle and unconscious sexism' which impacts upon 'work distribution, student evaluations, and promotion and hiring decisions' ${ }^{20}$ The literature suggests that this sexism is rooted in gender stereotyping and cognitive bias. For example, studies suggest that academic women find it harder to establish their competence than their male colleagues for a number of reasons. ${ }^{21}$ Objective standards tend to be applied rigorously to women and leniently to men. While men may be judged on potential, women are judged strictly on their accomplishments. Due to attribution bias, women's achievements may be attributed to luck, while their male colleagues' achievements are viewed as deserved. In addition to finding it harder to establish competence women may also be penalized for being 'too' competent if they upset submissive female stereotypes. Women may also, due to social isolation, not be aware of informal norms such as the unwritten rules of what behaviours are required to present an appearance of competence.

Discrimination potentially affects all women in universities but it has an especially detrimental impact on women who are mothers. The so-called motherhood penalty or the maternal wall is the strongest form of gender bias in today's workplace. ${ }^{22}$ Studies suggest that mothers are less likely to be hired, less likely to be promoted, are paid less and are held to higher performance and punctuality standards than non-mothers. ${ }^{23}$ The presence of the maternal wall in academia has been well documented. ${ }^{24}$

New Zealand universities have a moral and a legal responsibility to address discrimination against women. However, the persistence of gender inequality suggests that law and related policies are not functioning particularly well as a tool for addressing this inequality. In support of this proposition, a number of participants in a recent survey at a New Zealand university actively questioned the role of legal rights to non-discrimination, deeming them 'not helpful' in resolving challenges faced in their work lives, stressing the risks of undertaking such actions in terms of creating conflict with colleagues, or stating that they preferred to resolve issues at a personal

19 Susan Sturm, 'Second Generation Employment Discrimination: a Structural Approach' (2001) 101 Columbia Law Review 458, 469.

20 Jennifer Freyd and J Q Johnson, References on Chilly Climate for Women Faculty in Academe (2010) University of Oregon $<$ http://dynamic.uoregon.edu/ jjf/chillyclimate.html $>$.

21 See generally Joan Williams, Tamina Alon and Stephanie Bornstein, 'Beyond the 'Chilly Climate': Eliminating Bias Against Women and Fathers in Academe' (2006) The NEA Higher Education Journal 79, 79-86.

22 Joan Williams, Reshaping the Work-Family Debate: Why Men and Class Matter (Harvard University Press, 2010) 28.

23 See especially Shelly Correll and Stephen Bernard, 'Getting a Job: Is There a Motherhood Penalty?' (2007) 112 American Journal of Society 1297. See also Kessler, above n 8, 319.

24 Williams, Alon and Bornstein, above n 21, 83. 
level. ${ }^{25}$ Similarly a US survey reported that female faculty find legal mechanisms and direct political action of limited utility. ${ }^{26}$ Finally, according to Bird, typical diversity training programmes 'with a focus on reviewing laws and policies regarding illegal workplace practices and teaching employees how to avoid sexual and racial harassment' achieve 'little in terms of the necessary systemic transformation of university structures, practices and cultures'. ${ }^{27}$

Universities pose particular challenges in that they are characterised by complex decentred decision-making processes where matters such as promotions and appointments are delegated to various committees. As described by Bird these decentralised decision-making structures permit disjunctures between formally stated expectations and informal practices. These may often coincide with disjunctures between expectations and reward structures at university level and department level. ${ }^{28}$ Hence a high-level intention to (for example) prohibit bias or to not penalise staff for working part-time due to family commitments will not necessarily be implemented at a lower level.

To systematically change the culture and remove structural discrimination against women so as to ensure universities are fully in compliance with their legal obligations is a complex undertaking. This article does not purport to provide a comprehensive blueprint for change but instead addresses one piece of the puzzle.

\section{The Role of Voice in Addressing Discrimination}

One corrective to the disjuncture between high level directives and intentions and their lower level implementation is surely for concerned parties to speak about gender inequality. This is to exercise 'voice', which is defined as the opportunity to express ideas, to be listened to with respect, and potentially make a difference or proactively make suggestions for change..$^{29}$ For example, an individual sensitised to gender bias could, if appointed to an appointments or promotions committee, point out manifestations of bias. It need not necessarily be a woman that fulfils this role, although Bird suggests that the overrepresentation of men in important decision making positions 'increases the likelihood that what men take for granted as normal and appropriate will inform the ways in which they interpret the strategies for success and corresponding accomplishments of faculty'. ${ }^{30}$

25 Deborah Jones et al, 'Women Staff in Business Schools: An Exploratory Study' (Working Paper No 9-11, Victoria Management School, 4 January 2012) 13.

26 Kristen Monroe et al, 'Gender Equality in Academia: Bad News from the Trenches, and Some Possible Solutions' (2008) 6 Perspectives on Politics 215, 223.

27 Bird, above n 13, 211, citing Kalev et al, 'Best Practices or Best Guesses? Assessing the Efficacy of Corporate Affirmative Action and Diversity Practices' (2006) 71 American Sociological Review 589.

28 Ibid, 206; Williams, above n 22, 24.

29 Linn Van Dyne, Soon Ang and Isabel C Botero, 'Conceptualizing Employee Silence and Employee Voice as Multidimensional Constructs' (2003) 40 Journal of Management Studies 1359, 1370.

30 Bird, above n 13, 210. 
In the next section it is suggested that women do not all speak with one voice on matters concerning gender discrimination and they should not be expected to. This highlights the limitations of having token women serving on committees as a means of addressing structural discrimination.

\section{Women Do Not Speak with One Voice}

While it is important that women take part in decision-making committees there are some problematic aspects to this. Carol Gilligan has argued that women 'speak with a different voice' 31 which, broadly speaking, would suggest that the mere presence of a woman could bring a caring, relational, unified female perspective to the table. However, as noted by Williams, feminists have fought long and hard to establish biology is not destiny. Accordingly 'the assumption that women will join in automatic sisterhood reflects an unwarranted premise: that women are inevitably bound together by their experience of womanhood. [In fact] the experience of gender divides women as often as it unites them'. ${ }^{32}$ In short, women do not all naturally agree on issues of gender and nor do they necessarily see common cause with each other.

It is apparent that not all women in universities perceive discrimination. A recent study exploring the equity issues encountered by women in a New Zealand university found that while some participants saw women as disadvantaged relative to men others were reluctant to frame their experience in gender terms. Some participants strongly rejected the proposition that there were any gender differences in terms of opportunities. ${ }^{33}$

There are a number of possible explanations for this. Recent research on women and gender has identified the phenomenon of 'gender fatigue', that is, women are 'tired of seeing gender discrimination and prefer to see a world that is gender egalitarian, where gender no longer matters' ${ }^{34}$ This is so even in environments, such as universities, where objectively and statistically, it is quite apparent that women are unequal.

It is also possible that some very high achieving women may genuinely not have much personal experience of discrimination. Studies suggest that gender bias is a complex phenomenon in that women are not always and invariably assessed less favourably than their male colleagues. In fact, 'superstar' women tend to achieve better assessments than their male equivalents, while merely very good women feel the full force of gender bias in terms of lower assessments than their male equivalents. ${ }^{35}$

31 Carol Gilligan, In A Different Voice: Psychological Theory and Women's Development (Harvard University Press, 1982).

32 Williams, above n 22, 91.

33 Jones et al, above n 25, 12.

34 Elisabeth K Kelan, 'Gender Fatigue: the Ideological Dilemma of Gender Neutrality and Discrimination in Organisations' (2009) 26 Canadian Journal of Administrative Sciences 197, 198.

35 Williams, Alon and Bornstein above n 21, 81. 
Another relevant factor is that successful academic women often pay a higher price for success than their male counterparts. In an academic context, the ideal worker norm is embodied in a male academic who has little or no responsibility for the day to day care of dependents, who is willing and able to work whatever hours are required, as well as to travel frequently and extensively. Many academic women who have conformed to this ideal have sacrificed having children or have faced daily challenges struggling with the dual demands of work and motherhood. Having sacrificed so much these women 'have a lot invested in the view that being an ideal worker is what the job takes: otherwise, why did they sacrifice having children or having time with them?'36 They thus may have little sympathy with claims regarding discrimination or any attempts to find a middle ground where both men and women could expect some recognition of a need for work life balance or of family life.

The above analysis suggests that the mere presence of token women on committees will not ensure that consciousness will be raised regarding subtle forms of discrimination. In fact, representative women may not feel that discrimination is present due to not having experienced any personally. There is also a risk of 'queen bee syndrome'. This is a pattern of conflict among women which, as identified by Williams, occurs 'where one woman is taken into the in-group and fails to support or even targets other women'.37

The point that is that women do not all speak with one voice; however, this is not to argue that women should have to. Indeed, to place expectations on particular women to represent all women is symptomatic of their disadvantaged minority status. ${ }^{38}$ Members of majority groups are treated as individuals; it is only token members of minorities who are expected to represent that minority. If men and women were equal then women would have the same freedom as men to form and express idiosyncratic, individual views and would not be expected to represent, nor be held accountable to, the imagined sisterhood. It is also problematic (as well as ironic) that positive discrimination practices intended to give women more of a voice can mean that women do more work serving on committees than their male colleagues which is hardly equitable.

In the next section some of the factors which may operate to silence women, who perceive discrimination and wish to speak out against it, are outlined.

\section{Vi How the Chilly Climate Silences Women}

While some women may feel a sense of gender fatigue or an absence of discrimination others may have gender equality concerns. For these individuals a choice of whether to speak out or remain silent has to be made. Silence is the corollary of voice. In Van Dyne, Ang and Botero's taxonomy, silence is not simply an absence

\footnotetext{
$36 \quad$ Ibid 91.

37 Ibid.

38 Rosabeth Kanter, Men and Women of the Corporation (Basic Books, 1977). Kanter first, and most influentially, developed the concept of tokenism and explored its implications.
} 
of voice but refers to situations where employees intentionally withhold information. ${ }^{39}$ The choice of whether to speak up or remain silent will be made within the context of a social hierarchy that has implicit norms about the desirability of speaking up. ${ }^{40}$

Speaking up generally involves risk. Van, Ang and Botero note that 'prosocial' voice, that is, voice that is intentional, constructive and aimed at contributing to positive change involves personal risk and is not necessarily perceived positively by observers. Where those in authority are comfortable with the status quo they may not wish to hear about problems.$^{41}$ Consequently the decision to remain silent about problems is a fairly common one. ${ }^{42}$ Employees may withhold relevant ideas, information, or opinions if they believe that speaking up is unlikely to make a difference, or if they feel powerless to influence the situation. ${ }^{43}$ People who are lower in hierarchies (such as women) instinctively do not send bad news upstream. ${ }^{44}$ Employees may also be defensively silent. This is silence based on fear of the consequences of making suggestions for change. ${ }^{45}$ Employees may fear that speaking out will damage their image and that they will be negatively labelled and isolated and that their views may not be taken seriously. ${ }^{46}$ Someone who is labelled as a 'whiner' or 'troublemaker' will often be perceived as merely whining or trouble making when they raise concerns.

Women who speak out on gender equality issues have good reason to fear that doing so will result in negative consequences ${ }^{47}$ According to Williams, in sexist universities, in order to gain acceptance and avoid marginalisation women are frequently 'forced to play accepted feminine supporting roles: i.e. 'the mother' who is non-threatening and nurturing; the 'princess' who aligns with a stronger man; or the 'pet' who is perky and deferential'. She further suggests that 'in a culture in which men are expected to be assertive and powerful and women are expected to be sociable and reassuring a forceful woman who exercises authority is likely to be viewed in a negative light' ${ }^{48}$

39 Van Dyne, Ang and Botero, above n 29.

40 Frances J. Miliken and Elizabeth Wolfe Morrison, 'Shades of Silence: Emerging Themes and Future Directions for Research on Silence in Organisations' (2003) 40 Journal of Management Studies 1563.

41 Van Dyne, Ang and Botero, above n 29, 1371, citing Dennis W Organ, Organisational Citizenship Behaviour: The Good Soldier Syndrome (Lexington Books, 1988).

42 Frances J Milliken, Elizabeth W Morrison and Patricia F Hewlin, 'An Exploratory Study of Employee Silence: Issues that Employees Don't Communicate Upward and Why' (2003) 40 Journal of Management Studies 1453.

43 Van Dyne, Ang and Botero, above n 39, 1361. They refer to this form of silence as acquiescent voice.

44 Milliken, Morrison and Hewlin, above n 42, 1455, citing Leon Festinger, 'A Theory of Social Comparison Processes' (1954) 40 Human Relations 117.

45 Van Dyne, Ang and Botero, above n 29, 1367.

46 Milliken, Morrison and Hewlin, above n 42, 1470.

47 Ibid 1456

48 Williams, Alon and Bornstein, above n 21, 82. 
There are identifiable patterns in how debates over the presence or otherwise of discrimination in universities play out. ${ }^{49}$ While it is possible for both men and women to speak up regarding gender issues, if a women speaks up on gender equality issues affecting women people are more likely to ascribe self-serving motives to her. ${ }^{50}$ According to Prentice, since most men do not consciously act in discriminatory ways they frequently assume that claims concerning the chilly climate are false. ${ }^{51}$ It is also common for findings of systemic discrimination to be reinterpreted as direct accusations against specific individuals provoking aggressively defensive responses whereby the equality-seekers who have pointed to systemic discrimination are denied status and authority ${ }^{52}$ and sometimes vilified and demonised ${ }^{53}$ as 'the feminist police'. ${ }^{54}$ Rowan contends that 'the forms of discrimination now negotiated by academic women are a "new problem with no name": a form of violence that it is both emotionally and professionally dangerous to declare'. ${ }^{55}$

The chilly climate can also silence women in other, more subtle ways. One effect of the chilly climate is a sense of isolation and of not feeling 'at home' in the university. ${ }^{56}$ Unfortunately, these feelings of isolation are likely to reinforce silence on gender equality issues. Bowen and Blackmon argue that 'individuals will be more likely to speak up in organizations when they believe that others will support their position and they are likely to remain silent when they believe that others will not support their positions' ${ }^{57}$ Piderit and Ashford suggest that building coalitions is one way for individuals to manage risk to image in terms of 'selling an issue' to those above them in an organisational hierarchy'. ${ }^{58}$ However, individuals who feel isolated will not have a good sense of whether or not others will support their positions and they may struggle to build coalitions.

49 Susan Prentice, 'The Conceptual Politics of Chilly Climate Controversies' (2000) 12 Gender and Education 195.

50 Sandy Piderit and Susan Ashford, 'Breaking Silence: Tactical Choices Women Managers Make in Speaking Up About Gender Equity Issues' (2003) 40 Journal of Management Studies 1477, 1479.

51 Prentice, above n 49, 201.

52 Ibid 205.

53 Ibid 200.

$54 \quad$ Ibid 203.

55 Leonie Rowan, 'You Ought to Think Yourself Lucky My Girl, You're Alive and You've Got a Job: New Manifestations of Discrimination Against Women in Australian Universities' (Paper presented at the Joint New Zealand Association for Research in Education and Australian Association for Research in Education, Rotorua, New Zealand, 29 November 2009) 22, quoted in Mansfield and Julich, above n 7, 23.

56 Jones et al, above $\mathrm{n} 25,5$.

57 Miliken and Morrison, above n 40, 1565, citing Frances Bowen and Kate Blackmon, 'Spirals of Silence: The Dynamic Effects of Diversity on Organisational Voice' (2003) 40 Journal of Management Studies 1393.

$58 \quad$ Piderit and Ashford, above n 50, 1495. 
Sadly, silence on gender equality issues is likely to contribute to further negative consequences and disempowerment. Miliken and Morison suggest that the feeling of being unable to speak up about issues and concerns may result in a sense of helplessness and reduced job satisfaction. They also suggest that 'contagion' is a consequence of silence in organizational settings in that "what begins as silence about one issue can spread to become silence about a range of issues, .59

This silencing of employees, in this context of women who choose not to speak up about issues of gender discrimination, is problematic. Silence is easy to misinter$\operatorname{pret}^{60}$ and it leads to serious distortions in the knowledge on which decisions are made, leading to faulty decisions and the undermining of 'the reporting of unethical and illegal practice and the likelihood of effective organisational learning' ${ }^{61}$

\section{Conclusion}

The analysis above has a number of implications both for universities seeking to be compliant with the law and for those seeking a deeper understanding of how to design effective regulatory mechanisms which utilise voice to address structural and subtle forms of discrimination.

Voice has a role to play in terms of bridging the gap between formal regulation intended to address inequality and the informal norms which may subvert these good intentions. However, merely appointing token women to committees will not necessarily achieve this. As has been argued above women do not all speak with one voice and some may not see discrimination even when this is present for a variety of reasons. There are also, as has been identified above risks to individual women who might wish to voice concerns regarding the presence of discrimination.

Piderit and Ashford argue that 'top managers wishing to encourage open dialogues about gender-equality issues must find ways to immunize their members against image risk in order to get a clear reading of managers and employees levels of concern about gender equality issues' ${ }^{62}$ This may require training middle managers on the subtle forms that discrimination takes as well as on the forces that cause individuals to be silent.

Piderit and Ashford also suggest that coalition building is a way for individuals to immunise themselves against the backlash associated with raising gender related issues in organisations. ${ }^{63}$ This analysis suggests that unions may have a role to play as they could potentially provide a way for individuals to minimize personal risk by enabling them to raise gender equality issues collectively. However, it is important

\footnotetext{
$59 \quad$ Miliken and Morrison, above n 40, 1564.

60 Van Dyne, Ang and Botero, above n 29, 1359.

61 Miliken and Morrison, above n 40, 1563.

62 Piderit and Ashford, above n 50, 1498.

63 Ibid 1477
} 
that unions themselves ensure that organisers and other officials are suitably trained regarding gender equality issues and the need to protect individuals who raise gender equality concerns.

Finally, given the unfortunate reality of the phenomena of gender fatigue and the hostility towards gender-based claims, equality seekers in universities and elsewhere should give careful thought to when it might be appropriate to formulate claims in gender neutral terms in order to form coalitions around particular issues. For example women who resist discrimination claims may agree on the need for greater flexibility to accommodate family responsibilities. Many men might also be in agreement on this proposition and so it may be that, in this instance, a unified non gender-based claim might ultimately advance the cause of workplace equality more effectively than a gender-based claim could. 